\title{
Oxygenic Photoreactivity in Photosystem II Studied by Rotating Ring Disk Electrochemistry
}

\author{
Nikolay Kornienko, ${ }^{\dagger}$ Jenny Z. Zhang, ${ }^{\dagger}$ Katarzyna P. Sokol, ${ }^{\dagger}$ Sarah Lamaison, ${ }^{\dagger}$ Andrea Fantuzzi, \\ Rienk van Grondelle, A. William Rutherford, ${ }^{*}+$ and Erwin Reisner, ${ }^{\dagger}$ (i) \\ ${ }^{\dagger}$ Department of Chemistry, University of Cambridge, Lensfield Road, Cambridge CB2 1EW, U.K. \\ ${ }^{\ddagger}$ Department of Life Sciences, Imperial College London, South Kensington Campus, London SW7 2AZ, U.K. \\ ${ }^{\S}$ Department of Physics and Astronomy, VU Amsterdam, De Boelelaan 1105, $1081 \mathrm{HV}$, Amsterdam, The Netherlands
}

\section{Supporting Information}

\begin{abstract}
Protein film photoelectrochemistry has previously been used to monitor the activity of photosystem II, the water-plastoquinone photooxidoreductase, but the mechanistic information attainable from a three-electrode setup has remained limited. Here we introduce the four-electrode rotating ring disk electrode technique for quantifying lightdriven reaction kinetics and mechanistic pathways in real time at the enzyme-electrode interface. This setup allows us to study photochemical $\mathrm{H}_{2} \mathrm{O}$ oxidation in photosystem II and to gain an in-depth understanding of pathways that generate reactive oxygen species. The results show that photosystem II reacts with $\mathrm{O}_{2}$ through two main pathways that both involve a superoxide intermediate to produce $\mathrm{H}_{2} \mathrm{O}_{2}$. The first pathway involves the established chlorophyll triplet-mediated formation of singlet oxygen, which is followed by its reduction to superoxide at the electrode surface. The second pathway is specific for the enzyme/electrode interface: an exposed antenna chlorophyll is sufficiently close to the electrode for rapid injection of an electron to form a highly reducing chlorophyll anion, which reacts with $\mathrm{O}_{2}$ in solution to produce $\mathrm{O}_{2}{ }^{\bullet-}$. Incomplete $\mathrm{H}_{2} \mathrm{O}$ oxidation does not significantly contribute to reactive oxygen formation in our conditions. The rotating ring disk electrode technique allows the chemical reactivity of photosystem II to be studied electrochemically and opens several avenues for future investigation.
\end{abstract}

\section{INTRODUCTION}

Photosynthetic organisms convert light, $\mathrm{H}_{2} \mathrm{O}$, and $\mathrm{CO}_{2}$ into energy-rich carbohydrates and $\mathrm{O}_{2}$ gas. This process enabled the transformation of the primitive Earth to one with an $\mathrm{O}_{2}$ rich atmosphere and fossil fuel containing crust. Understanding the photosynthetic process can provide clues as to how life on Earth emerged through its evolution, while also providing a framework for how we can mimic photosynthesis to sustainably use solar energy. Within this context, we have focused on the enzyme that carries out light-driven $\mathrm{H}_{2} \mathrm{O}$ oxidation to $\mathrm{O}_{2}$, photosystem II (PSII). As it is the only protein complex capable of catalyzing this reaction, much effort has been directed toward studying its mechanisms of $\mathrm{H}_{2} \mathrm{O}$ oxidation catalysis, ${ }^{1}$ as well as light absorption, energy transfer, ${ }^{2}$ and charge separation. ${ }^{3}$

The large-scale oxidation of water and the consequent formation of an $\mathrm{O}_{2}$-rich atmosphere have also forced life to adapt to surviving in the presence of $\mathrm{O}_{2}$. Of additional interest is the resilience of PSII in an oxygenic environment, in which biologically harmful reactive oxygen species (ROS) are readily generated from $\mathrm{O}_{2}$ (Figure 1A). There are two main types of ROS considered here: (i) the reduced oxygen species, $\mathrm{O}_{2}{ }^{\bullet-}$, and $\mathrm{H}_{2} \mathrm{O}_{2}$ originate from electron transfer from redox-active cofactors of PSII to $\mathrm{O}_{2}$. Suggested sources include $Q_{A}, Q_{B}$, pheophytin, and cytochrome $b_{559 \cdot}{ }^{4}$ A special case of ROS formation is the proposed generation of $\mathrm{H}_{2} \mathrm{O}_{2}$ from incomplete $\mathrm{H}_{2} \mathrm{O}$ oxidation. (ii) Another type of ROS, ${ }^{1} \mathrm{O}_{2}$, originates from energy transfer from chlorophyll triplet states to ${ }^{3} \mathrm{O}_{2}{ }^{5}$ Deciphering these pathways in vivo is important for understanding the resilience of photosynthetic organisms under high stress conditions. In response to the generation of ROS, photosynthetic species have evolved various protection mechanisms, including redox tuning and ROS scavenging, which are key to their survival. ${ }^{6}$

Quantitative methods to study PSII activity and ROS generation have been developed to obtain an understanding of the in vivo function of this enzyme. Methods to detect oxygen include gas chromatography, Clark-type electrodes, and fluorescent sensors. There are also many methods to detect ROS, which include the use of spin trap compounds coupled

Received: August 15, 2018

Published: September 6, 2018 
A
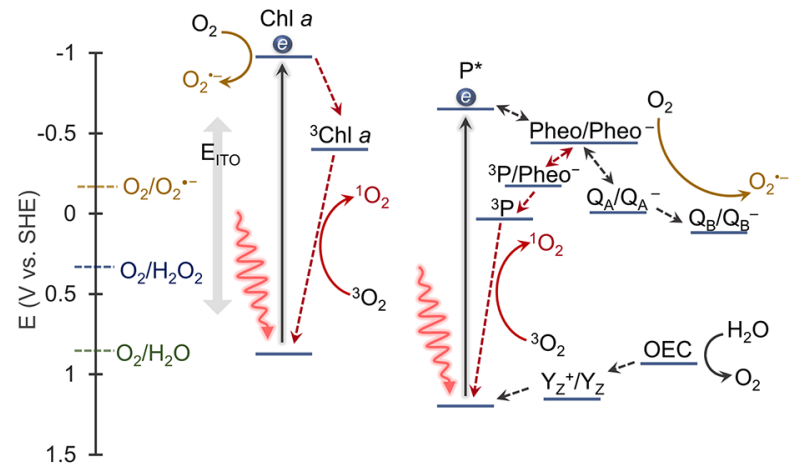

C
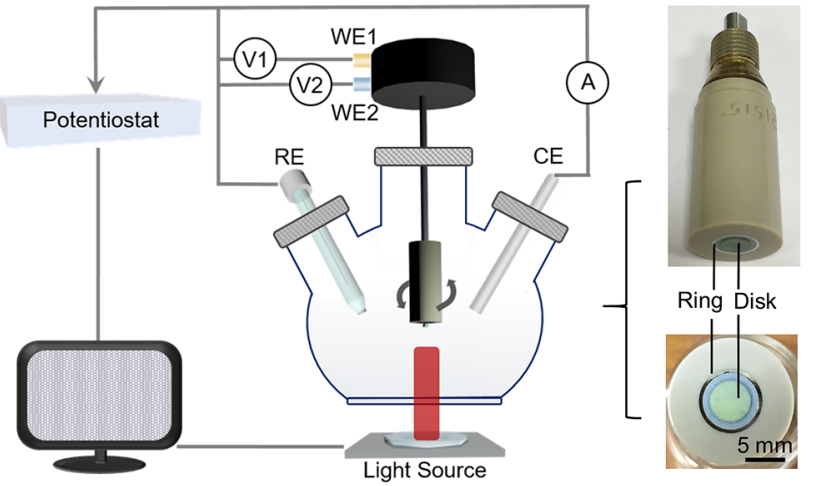

B

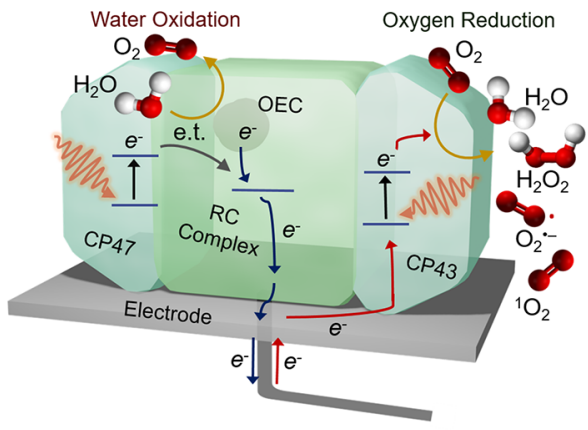

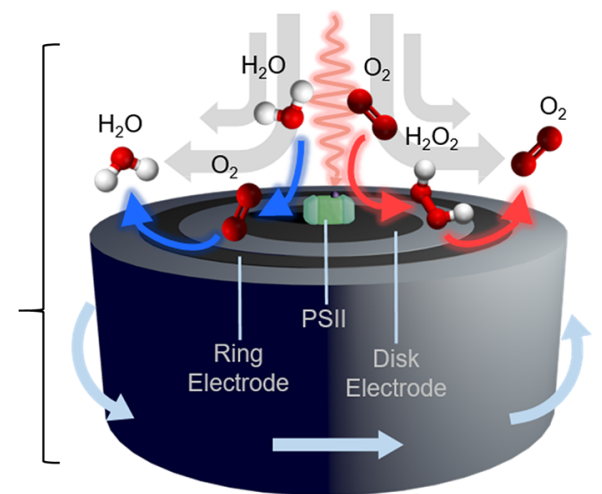

Figure 1. Reaction pathways for ROS formation and schematic representation of the rotating ring disk electrode (RRDE). (A) ROS can be generated by energy transfer from chlorophyll triplets or by electron transfer from chlorophyll and redox-active cofactors. The energy levels ( $\mathrm{pH}$ 6.5) of the $\mathrm{O}_{2}$ relevant redox potentials, light absorbers, and charge-carrying intermediates are illustrated in A. (B) To study $\mathrm{H}_{2} \mathrm{O}$ oxidation and ROS generation processes, we measure with protein film photoelectrochemistry charge injected into and out of the enzyme in the presence of $\mathrm{O}_{2}$ through fixing PSII onto a conductive electrode. e.t. signifies energy transfer. The RRDE technique, using two working electrodes, allows quantification of reaction products by reducing or oxidizing them as they are swept from disk to ring electrode. (C) Schematic representation of the setup.

with electron paramagnetic resonance spectroscopy, ${ }^{4,5}$ luminescence, ${ }^{7}$ mass spectrometry, ${ }^{8}$ and electrochemistry.

Protein film photoelectrochemistry serves as a quantitative probe of electron transfer reactions in PSII by measuring lightinduced electron transfer to or from the enzyme adsorbed on a conductive electrode (Figure 1B). ${ }^{11-18} \mathrm{H}_{2} \mathrm{O}$ oxidation activity is quantified through anodic (electron transfer from PSII to the electrode) photocurrents. ${ }^{19}$

In addition to $\mathrm{H}_{2} \mathrm{O}$ oxidation, an oxygen reduction pathway was recently reported as arising at the enzyme-electrode interface. ${ }^{17}$ This was evidenced by cathodic (electron transfer from the electrode to PSII) photocurrents in the presence of oxygen and was suggested to originate from electron transfer from the electrode to the excited chlorophyll, forming a chlorophyll anion, which then reduces $\mathrm{O}_{2} \cdot{ }^{17}$ In view of the likely presence of ${ }^{1} \mathrm{O}_{2}$ generated by chlorophyll triplet states, ${ }^{5,6}$ a second, or indeed alternative, origin of the cathodic photocurrents is the reduction of ${ }^{1} \mathrm{O}_{2}$. Clarification of the precise mechanism(s) behind the cathodic photocurrents is important for the understanding of the PSII-electrode interface and for the use of protein film photoelectrochemistry as a tool for studying PSII enzymology.

In the field of protein film electrochemistry, rotating disk electrode (RDE) measurements are a valuable tool for precise electrochemical quantification of enzyme catalysis with fast turnover frequencies (TOFs), providing a controlled convectional flux of reactants toward the enzyme-loaded electrode. $^{20-22}$ The rotating ring disk electrode (RRDE) method extends the capacity of $\mathrm{RDE}$ experiments by incorporating a second working electrode surrounding the disk to electrochemically quantify reaction products formed at the disk. The reaction products are hydrodynamically driven from the disk to the ring electrode due to the rotation of the apparatus. ${ }^{23-25}$

In this work, we have applied the RRDE method to PSII protein film photoelectrochemistry to measure photocurrents and the resulting reaction products from $\mathrm{H}_{2} \mathrm{O}$ oxidation and cathodic ROS generation (Figure 1C). The RRDE technique offers a new approach in PSII studies because it allows for the real-time $(\sim \mathrm{ms})$ analysis of reaction pathways without the necessities of high currents ( $\sim \mathrm{nA}$ sensitivity) and bulk product accumulation, during which a species of interest may be lost by further reactions with the enzyme or solution. This work demonstrates that PSII $\mathrm{H}_{2} \mathrm{O}$ oxidation and the resulting $\mathrm{O}_{2}$ generation can be quantitatively measured with the RRDE technique. This method was then used to show that photocathodic currents can distinguish between the two ROS-generating pathways, one in which $\mathrm{O}_{2}$ is directly reduced by electron transfer from a chlorophyll $a(\mathrm{Chl} a)$ anion radical formed by electron injection from the electrode into the $\mathrm{Chl}$ $a^{*}$ and the second by the reduction of ${ }^{1} \mathrm{O}_{2}$ formed by the reaction with ${ }^{3} \mathrm{O}_{2}$ with the chlorophyll triplet, which is one of the main causes of photodamage in photosystem II. $^{5}$ We further show that $\mathrm{H}_{2} \mathrm{O}_{2}$ ROS can be generated and quantified without the need for an electrode to electrochemically reduce the protein, indicating that the results of this study may be translated to PSII behavior in vivo. 

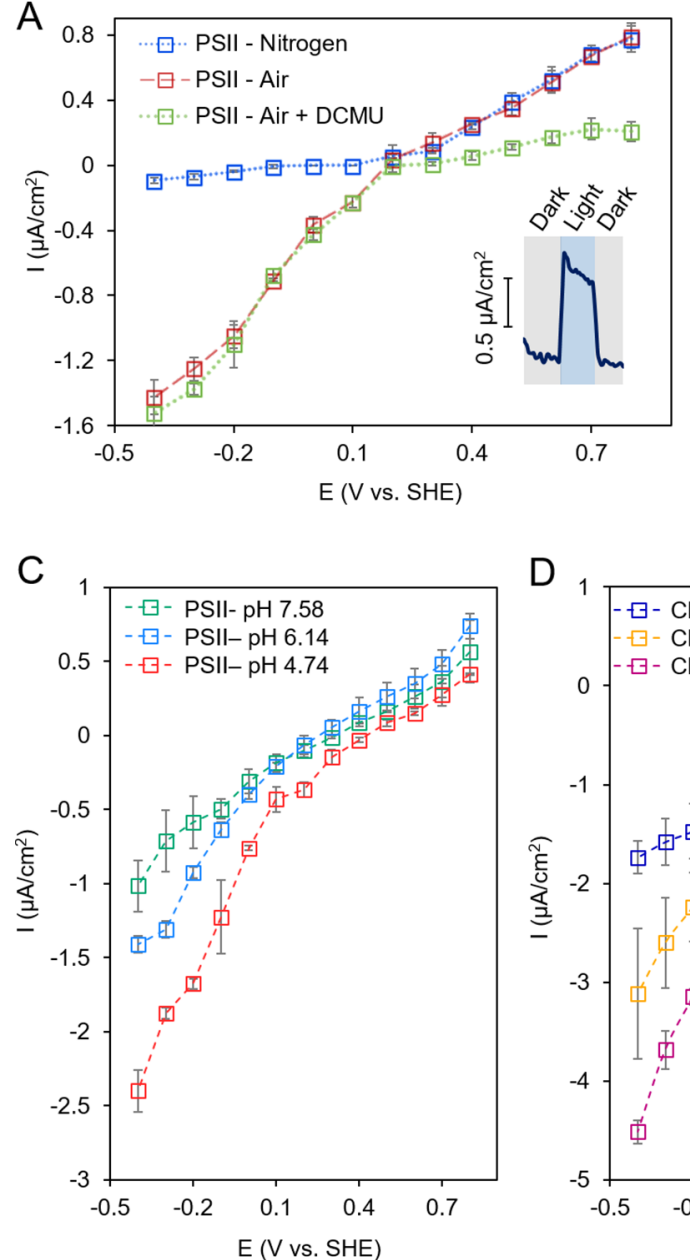
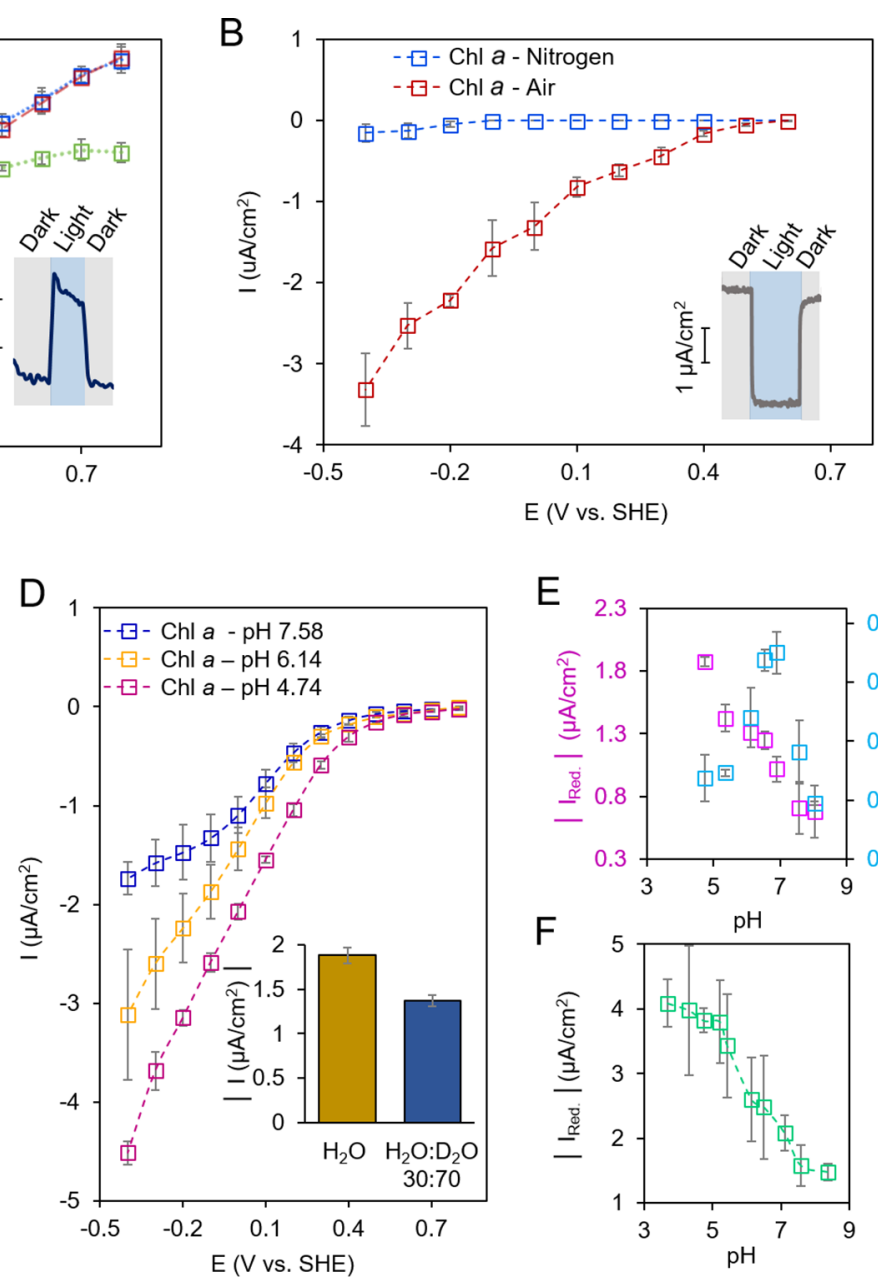

Figure 2. Study of immobilized PSII and Chl $a$ activity on a RDE. At pH 6.5 under chopped $8 \mathrm{~mW} \mathrm{~cm}{ }^{-2} 660 \mathrm{~nm}$ illumination, PSII (A) and Chl $a$ (B) exhibit a cathodic current only in an air-saturated electrolyte solution. The plots show background-corrected photocurrents. The insets in A and B illustrate a typical photoresponse for PSII at $0.6 \mathrm{~V}$ (A) and for Chl $a$ at $-0.3 \mathrm{~V}$ (B) vs SHE. Upon varying solution $\mathrm{pH}$ from 4.74 to 7.58 , PSII (C) and Chl $a$ (D), photocurrents increase at lower $\mathrm{pH}$ values. A kinetic isotope effect upon the addition of deuterated buffer was observed (inset of D). Both PSII (E) and $\mathrm{Chl} a(\mathrm{~F})$ exhibit an enhanced cathodic current $\left(I_{\text {Red. }}\right.$ ) at $-0.3 \mathrm{~V}$ vs SHE at lower $\mathrm{pH}$, whereas the anodic $\mathrm{H}_{2} \mathrm{O}$ oxidation current $\left(I_{\mathrm{Ox}}\right)$ at $0.6 \mathrm{~V}$ vs SHE in PSII is maximized at $\mathrm{pH}$ 6.5-6.9.

\section{RESULTS}

We started with three-electrode RDE studies of isolated PSII on a mesoporous indium tin oxide (ITO) film and comparing the photoelectrochemical response to $\mathrm{Chl} a$ on a planar glassy carbon electrode as a simplified model system. The chlorophyll content was quantified by UV-vis spectrophotometry (Figure S1). The electrode was exposed to chopped (intermittent) illumination with an applied bias potential ranging from 0.8 to $-0.4 \mathrm{~V}$ vs the standard hydrogen electrode (SHE), and the resulting photocurrents were recorded (Figure 2). When PSII was immobilized on an electrode, two types of photocurrents were observed: anodic photocurrent originating from lightinduced electron transfer to the PSII acceptor side (to $Q_{A}$ or $\mathrm{Q}_{\mathrm{B}}$ ) driven by water oxidation and cathodic photocurrents linked to $\mathrm{O}_{2}$ reduction. The anodic response has been analyzed in detail previously, ${ }^{12,13,16,19}$ and the cathodic currents are the primary focus of study in this work. At an applied potential more negative than $0.2 \mathrm{~V}$ (for PSII) and $0.5 \mathrm{~V}$ (for Chl $a$ ) vs SHE, both samples exhibited a cathodic photocurrent, as previously reported (Figure $2 \mathrm{~A}, \mathrm{~B}) .{ }^{17}$ This occurs in an airsaturated electrolyte solution but not under $\mathrm{N}_{2}$, indicating the involvement of $\mathrm{O}_{2}$. Inhibiting the $\mathrm{H}_{2} \mathrm{O}$ oxidation photo- currents with the $\mathrm{Q}_{\mathrm{B}}$ inhibitor 3-(3,4-dichlorophenyl)-1,1dimethylurea (DCMU) did not result in a decrease of cathodic photocurrents (Figure 2A).

We next probed the effects of $\mathrm{pH}$ on cathodic $\left(\mathrm{O}_{2}\right.$ reduction) and anodic $\left(\mathrm{H}_{2} \mathrm{O}\right.$ oxidation) photocurrents for PSII and Chl a (Figure 2C-F). The $\mathrm{O}_{2}$ evolution activity (anodic photocurrents) was maximized at $\mathrm{pH}$ 6.5-6.9 for PSII and decreases at lower and higher $\mathrm{pH}$ values. This trend is similar to those previously observed in in vitro studies and stems from the interplay of $\mathrm{H}_{2} \mathrm{O}$ oxidation catalysis and kinetics of electron transfer through the quinone acceptors. ${ }^{26}$

Both PSII and Chl $a$ exhibited increased cathodic photocurrents in lower $\mathrm{pH}$ electrolyte solutions, which supports the involvement of protons in the photocathodic reaction pathway. This is supported by a kinetic isotope effect (KIE) of approximately 1.4 for $\mathrm{Chl} a$ (Figure 2D inset). However, KIEs as high as 3.4 have been observed for electrochemical $\mathrm{O}_{2}$ reduction limited by proton-coupled steps, suggesting the ratedetermining step $(\mathrm{s})$ in our system are not proton-coupled. ${ }^{27,28}$ This observation points to the generation of $\mathrm{O}_{2}^{\bullet-}$ as a ratelimiting step, followed by proton-dependent steps in $\mathrm{H}_{2} \mathrm{O}_{2}$ or $\mathrm{H}_{2} \mathrm{O}$ generation. 

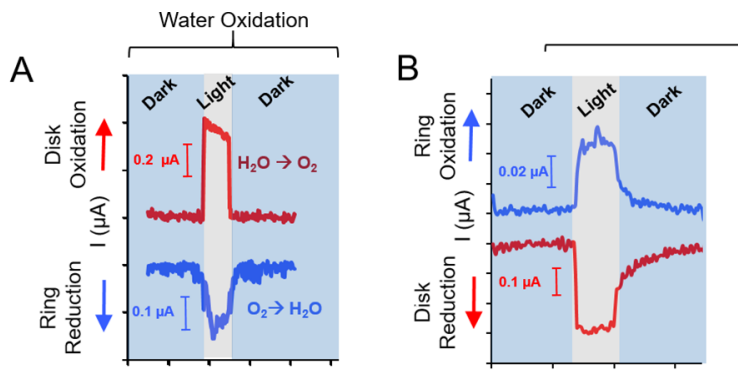

Oxygen Reduction

$\mathrm{E}$
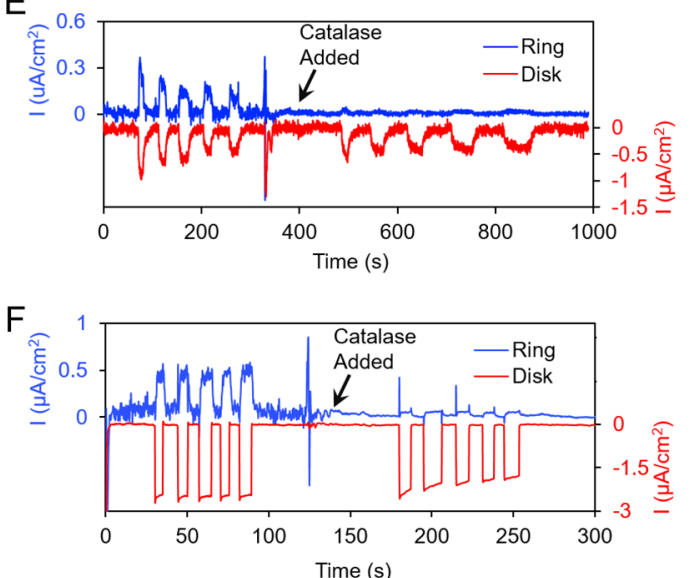

D
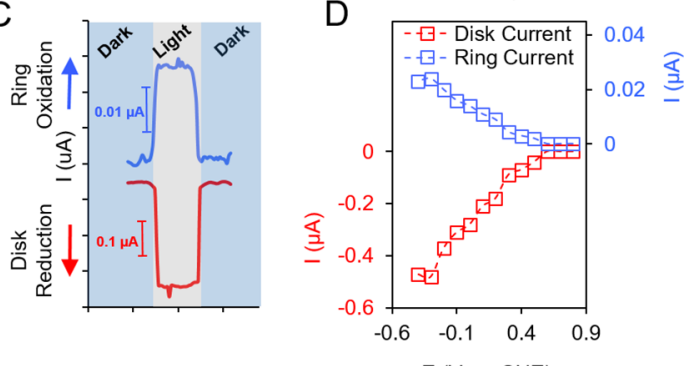

G

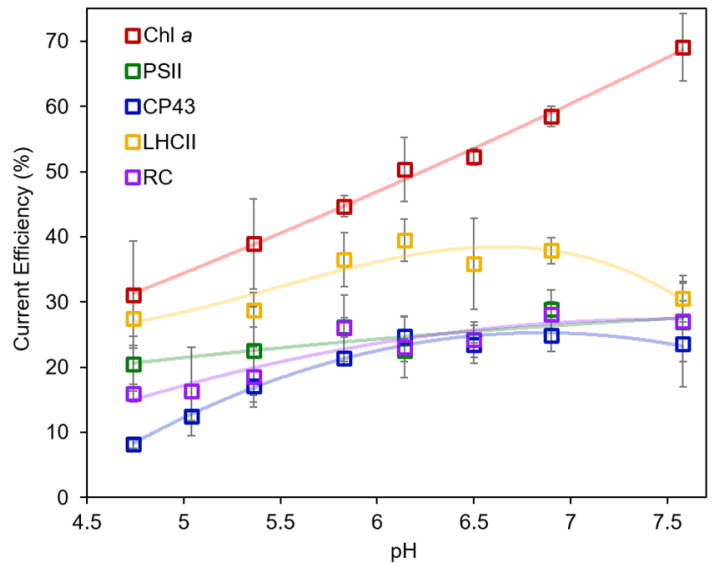

Figure 3. $\mathrm{H}_{2} \mathrm{O}$ oxidation and ROS generation measured by the RRDE setup. (A) $\mathrm{H}_{2} \mathrm{O}$ oxidation and the resultant $\mathrm{O}_{2}$ produced were first measured for PSII. Cathodic disk currents from PSII (B) and Chl $a$ (C) were accompanied by anodic ring currents. (D) Their magnitudes (shown for Chl $a$ ) scaled with each other at an applied potential of 0.5 to $-0.5 \mathrm{~V}$ vs SHE to the disk electrode and $0.9 \mathrm{~V}$ vs SHE to the ring electrode. The addition of catalase to PSII (E) and Chl $a(\mathrm{~F})$ electrodes suppressed the majority of the ring photocurrents (applied potentials of $-0.5 \mathrm{~V}$ to the disk and $0.9 \mathrm{~V}$ to the ring electrodes, $\mathrm{pH}$ 6.5). (G) The ROS current efficiency for Chl a, PSII, the CP43 and LHCII antenna subunits, and RC was pHdependent, with the proteins exhibiting lower $\mathrm{H}_{2} \mathrm{O}_{2}$ production compared to $\mathrm{Chl} a$.

After examining PSII and Chl $a$ with the RDE, we investigated the reaction products with our RRDE setup, using a Pt ring electrode to reduce or oxidize products formed at the disk electrode. This configuration consisted of a glassy carbon or mesoporous ITO disk (working electrode 1, WE 1), platinum ring (WE 2), $\mathrm{Ag} / \mathrm{AgCl}$ reference (RE), and glassy carbon counter (CE) electrodes in a one-compartment electrochemical cell, which was illuminated from the bottom with a $660 \mathrm{~nm}$ light-emitting diode (LED) $\left(8 \mathrm{~mW} \mathrm{~cm}{ }^{-2}\right.$; Figure $1 \mathrm{C})$. The rotation of the working electrode apparatus draws in reactants (e.g., $\mathrm{O}_{2}$ ) to the disk electrode, and a quantifiable fraction (defined by the collection efficiency, Figure S2) of the reaction products (e.g., $\mathrm{O}_{2}$ or $\mathrm{H}_{2} \mathrm{O}_{2}$ ) flow to the ring electrode. The electrochemical potential on the ring electrode is set to carry out only the reaction of interest (e.g., $\mathrm{H}_{2} \mathrm{O}_{2}$ oxidation). The collection efficiency was quantified using a ferri/ferrocyanide redox couple as well as $\mathrm{H}_{2} \mathrm{O}$ oxidation/ $\mathrm{O}_{2}$ reduction. The fraction of photocurrent directed toward a particular product is quantified by the ratio of ring to disk currents and is dependent on the electrode geometry (Figures S2, S3).

We first quantified the activity of PSII for photoanodic $\mathrm{H}_{2} \mathrm{O}$ oxidation by PSII (at the disk) by reducing (at the ring electrode) the $\mathrm{O}_{2}$ liberated. When the disk was biased at $0.5 \mathrm{~V}$ vs SHE in a nitrogen-purged $\mathrm{pH} 6.5$ electrolyte solution (to avoid bulk $\mathrm{O}_{2}$ reduction from the ring electrode) and illuminated with $660 \mathrm{~nm}$ light, an anodic current stemming from electron transfer from PSII to the electrode during $\mathrm{H}_{2} \mathrm{O}$ oxidation was observed at the disk electrode. The anodic disk current was accompanied by a cathodic ring current (Figure $3 \mathrm{~A}$ and Figures S4, S5). Quantifying the photocurrent ratios revealed that $\mathrm{O}_{2}$ was produced with a faradaic efficiency of 94$98 \%$. Direct quantification of $\mathrm{O}_{2}$ generation at the enzymeelectrode interface may open up possibilities for studying, in real time, PSII photoactivation and $\mathrm{H}_{2} \mathrm{O}$ oxidation photocatalysis of PSII enzymes with reconstituted Mn clusters or with synthetic water oxidation catalysts inserted in place of the Mn cluster in future studies. ${ }^{29}$ Next, we investigated the reaction pathways that led to cathodic photocurrents at the disk electrode. Cathodic photocurrents can potentially stem from electron transfer from the chlorophylls to $\mathrm{O}_{2}$ to generate $\mathrm{O}_{2}{ }^{\bullet-}$ and $\mathrm{H}_{2} \mathrm{O}_{2}{ }^{17}$ According to the proposed mechanism, electron injection from the electrode into a nearby photoexcited chlorophyll ground state would produce a relatively long-lived chlorophyll anion. This very reducing chlorophyll anion could then easily transfer an electron to $\mathrm{O}_{2}$. An alternative pathway consists of the well-known generation of ${ }^{1} \mathrm{O}_{2}$ via energy transfer from chlorophyll triplets to ${ }^{3} \mathrm{O}_{2}$ and subsequent electron transfer on the electrode surface to ${ }^{1} \mathrm{O}_{2}$. The generation of a chlorophyll triplet in PSII is considered to be the main source of photodamage. ${ }^{5,6}$ The initial chlorophyll triplet formation is not thought to be due to standard intersystem crossing from the excited singlet chlorophylls but from the radical pair recombination mechanism in the heart of the reaction center (Figure $1 \mathrm{~A}) .^{30}$

In the presence of $\mathrm{O}_{2}$, a light-driven cathodic disk current was accompanied by an anodic ring photocurrent for PSII and $\mathrm{Chl} a$ (Figure 3B-D). The disk and ring currents scaled with 

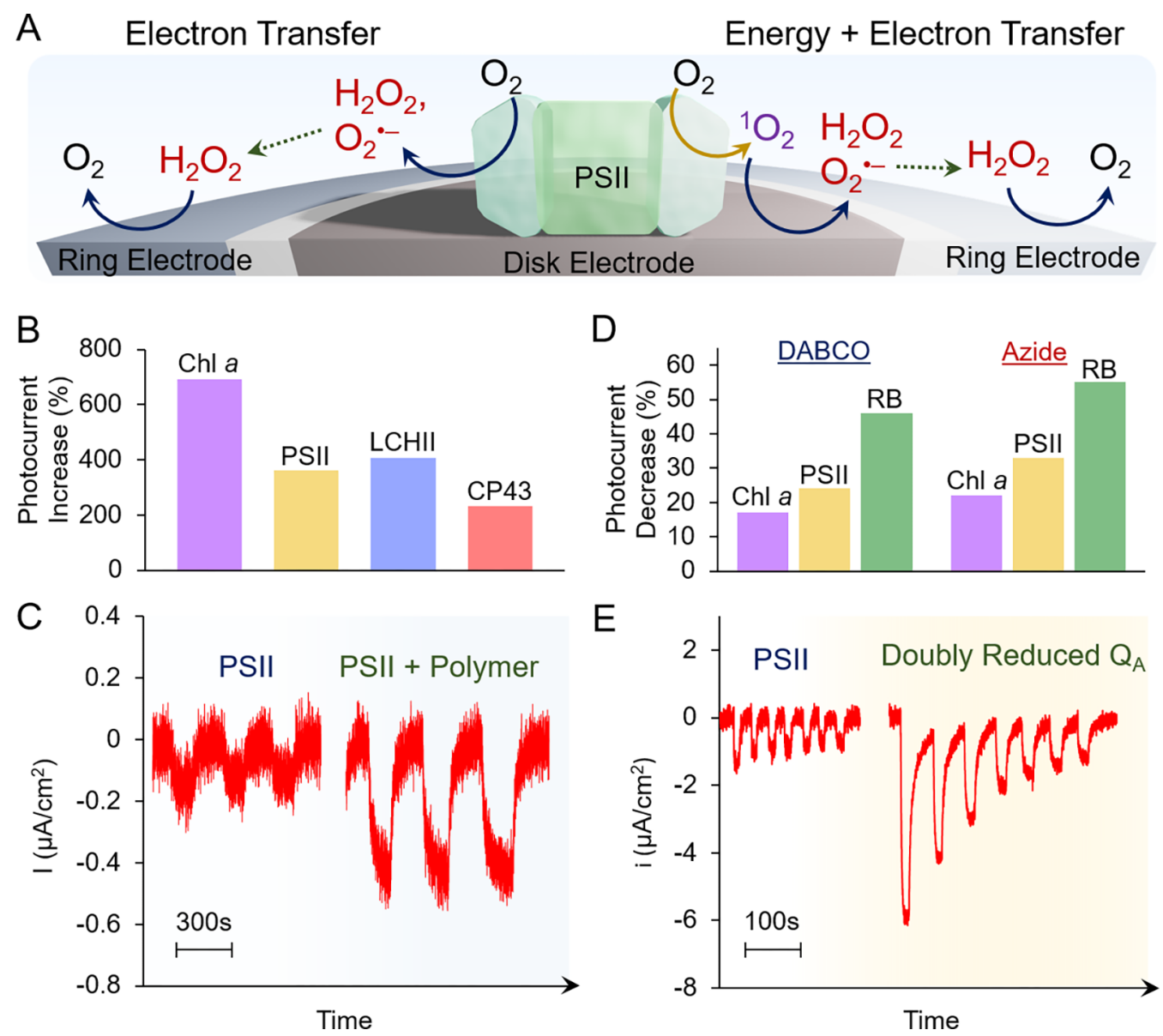

Figure 4. Pathways of oxygen reduction. (A) PSII may interact with oxygen through an electron transfer pathway or through a ${ }^{1} \mathrm{O}_{2}$ involving an energy and electron transfer pathway. (B, C) The electron transfer pathway can be increased by embedding PSII and its constituent units in a conductive polymer to wire it to the electrode more efficiently ( $\mathrm{pH} 6.5,0.1 \mathrm{~V}$ vs SHE). The photocurrent increase is compared to the photocurrent of $\mathrm{Chl} a$ and proteins observed without the use of the polymer. (D) ${ }^{1} \mathrm{O}_{2}$ generation and disk photocathodic current from its subsequent reduction were partially suppressed through the inclusion of $10 \mathrm{mM} \mathrm{DABCO}$ or azide water-soluble quenchers ( $\mathrm{pH} 6.5,-0.3 \mathrm{~V}$ vs SHE). The photocurrent decrease is relative to that observed prior to quencher addition. On the other hand, the energy transfer pathway was preferentially enhanced by doubly reducing $\mathrm{Q}_{\mathrm{A}}$ with a dithionite and light treatment to promote radical pair recombination generation of chlorophyll triplet in PSII and to extend the lifetime of the chlorophyll triplet. (E) Both of these effects promote ${ }^{1} \mathrm{O}_{2}$ generation, and this increases photocathodic currents through the subsequent reduction of this species $(\mathrm{pH} 6.5,-0.3 \mathrm{~V}$ vs SHE). All measurements were performed in an ambient air environment.

one another across -0.4 to $0.4 \mathrm{~V}$ vs SHE (Figure 3D), indicating that the currents at the ring were induced by products formed at the disk.

We next investigated the nature of the reactions responsible for the anodic currents stemming from our ring electrode. First, we added catalase, an enzyme that dismutates $\mathrm{H}_{2} \mathrm{O}_{2}$ into $\mathrm{H}_{2} \mathrm{O}$ and $\mathrm{O}_{2}$, to the electrolyte solution. Catalase addition quenched $\sim 90 \%$ of the ring current, implying that the oxidation of $\mathrm{H}_{2} \mathrm{O}_{2}$ is the dominant reaction at the ring electrode (Figure 3E,F and Figures S6, S7). $\mathrm{H}_{2} \mathrm{O}_{2}$ from the bulk solution was also detected with a fluorescent assay from the bulk solution (Figure S7). However, any $\mathrm{H}_{2} \mathrm{O}$ generated from the reduction of $\mathrm{O}_{2}$ or ROS would not be detected at the ring electrode. The addition of superoxide dismutase (SOD), which dismutates $\mathrm{O}_{2}^{\bullet-}$ to $\mathrm{O}_{2}$ and $\mathrm{H}_{2} \mathrm{O}_{2}$, to the electrolyte solution decreased the cathodic photocurrents by $\sim 20 \%$, suggesting that $\mathrm{O}_{2}{ }^{\bullet-}$ is involved in the reaction pathway(s) (Figure S8). Because $\mathrm{O}_{2}^{\bullet-}$ may also dismutate spontaneously in solution or be further reduced by the negatively biased electrode to generate $\mathrm{H}_{2} \mathrm{O}_{2}$, we cannot yet quantify how much of the $\mathrm{H}_{2} \mathrm{O}_{2}$ is produced from $\mathrm{O}_{2}{ }^{\bullet-}$.
The relative current ratios of the ring to disk electrodes (taking into account the electrode's collection efficiency) were measured for Chl a, PSII, the CP43 and LHCII antennae, which are chlorophyll-containing components of PSII, and the $\mathrm{D} 1-\mathrm{D} 2$ reaction center $(\mathrm{RC})$. In our setup, the current ratio for $\mathrm{H}_{2} \mathrm{O}_{2}$ production increased with increasing $\mathrm{pH}$ for all of the samples investigated. However, $\mathrm{Chl} a$ exhibited the steepest slope $\left(\mathrm{H}_{2} \mathrm{O}_{2}\right.$ current ratio vs $\left.\mathrm{pH}\right)$ and the largest overall $\mathrm{H}_{2} \mathrm{O}_{2}$ production rates in comparison to the chlorophyll-containing proteins.

Control experiments with the antennae suggest that cathodic photocurrents stem primarily from the chlorophylls rather than other redox-active cofactors in PSII. This current ratio did not significantly change with applied bias, with the presence/ absence of 2-( $N$-morpholino)-ethanesulfonic acid (MES) in the electrolyte solution, or with white light (more closely matching the solar spectrum) vs $660 \mathrm{~nm}$ illumination (Figures S9, S10). The ring/disk current ratios also did not significantly change upon systematically modulating the $\mathrm{O}_{2}$ content in the electrolyte solution, suggesting that the observed reaction pathways are similar under the experimental range of $\mathrm{O}_{2}$ concentrations (1.25 to $0.04 \mathrm{mM}$ ) (Figure S10). Increased 
$\mathrm{H}_{2} \mathrm{O}_{2}$ production by $\mathrm{Chl} a$ relative to the other samples points to differing reaction mechanisms, reflecting the chemical environment of the chlorophylls in the proteins (Figures 3G and S11).

The following experiments were conducted to investigate the reaction pathways resulting in $\mathrm{H}_{2} \mathrm{O}_{2}$. Perturbed or chemically modified PSII has been reported to produce $\mathrm{H}_{2} \mathrm{O}_{2}$ from incomplete water oxidation. ${ }^{8,31-35}$ To probe for ROS formation during incomplete $\mathrm{H}_{2} \mathrm{O}$ oxidation in our system, we performed $\mathrm{H}_{2} \mathrm{O}$ oxidation at the PSII-loaded disk electrode at a bias of $0.6 \mathrm{~V}$ vs SHE. At the same time, we poised the ring electrode at $0.8 \mathrm{~V}$ vs $\mathrm{SHE}$ to oxidize any $\mathrm{H}_{2} \mathrm{O}_{2}$ that would be formed at the disk during this process. We did not observe significant amounts of ROS in this configuration (Figure S12), which is consistent with the essentially quantitative faradaic yield for $\mathrm{H}_{2} \mathrm{O}$ oxidation to $\mathrm{O}_{2}$ (see above). Furthermore, there were no measurable differences in disk/ring current ratios of intact PSII and Mn-depleted PSII (Figure S13). If a significant quantity of $\mathrm{H}_{2} \mathrm{O}_{2}$ originated from the oxygen evolving complex (OEC), then we should have observed relatively more $\mathrm{H}_{2} \mathrm{O}_{2}$ oxidation at the ring electrode. We therefore conclude that the primary source of $\mathrm{H}_{2} \mathrm{O}_{2}$ did not originate from incomplete water oxidation by PSII. Future applications of the rotating ring disk electrode technique can be used to probe donor-side ROS generation from PSII samples that had undergone specific treatments to induce partial $\mathrm{H}_{2} \mathrm{O}$ oxidation. ${ }^{31-35}$

Two likely reaction pathways toward $\mathrm{H}_{2} \mathrm{O}_{2}$ generation as a product of the cathodic photocurrents seem possible. Both pathways involve the formation of $\mathrm{O}_{2}{ }^{\bullet-}$, which then dismutates or is reduced to $\mathrm{H}_{2} \mathrm{O}_{2}$ : (i) the direct electron transfer from the chlorophyll anion (formed by electron injection into the excited state chlorophyll exposed to the electrode in PSII and isolated $\mathrm{Chl} a$ ) to $\mathrm{O}_{2}$ to generate $\mathrm{O}_{2}{ }^{\bullet-17}$ and (ii) $\mathrm{O}_{2}{ }^{\bullet-}$ generation from the reduction of ${ }^{1} \mathrm{O}_{2}$, generated from the chlorophyll triplet (in PSII or isolated Chl $a$ ) (Figures 4A and S14). The disk/ring current ratios remained relatively unchanged over a measurement period of 10-20 min for Chl $a$ and PSII, suggesting that the $\mathrm{H}_{2} \mathrm{O}_{2}$ generation is a continuous process rather than one involving a ROS scavenger (Figure $\mathrm{S} 15$ ).

For $\mathrm{O}_{2}$ reduction to proceed through electron transfer to $\mathrm{O}_{2}$ from any antenna chlorophylls, the chlorophyll anion formation needs to occur rapidly through fast electron injection into the chlorophyll ground state during the lifetime of the excited state, and this would likely proceed when the Chl $a$ is near the electrode. Only a limited surface of the enzyme is expected to be in direct electrical contact with the conductive electrode, and electron transfer to $\mathrm{O}_{2}$ is limited because electron injection into the majority of excited antenna Chl $a$ does not occur to a significant extent before excitation is lost due to excitation transfer or its relaxation to the ground state. Therefore, embedding PSII in a redox polymer or conductive matrix should enhance the rate of ground state regeneration and consequently the rate of electron transfer to $\mathrm{O}_{2}{ }^{17}$ To test this hypothesis, we drop cast a PSII-poly(1-vinylimidazole-coallylamine $)-\mathrm{Os}(\text { bipy })_{2} \mathrm{Cl}\left(\mathrm{P}_{\mathrm{os}}\right)$ redox polymer ${ }^{16}$ blend (1:1 (v/ v) PSII stock to $10 \mathrm{mg} \mathrm{mL}^{-1}$ polymer) on the ITO disk electrode and compared the magnitude to an equivalent $\mathrm{P}_{\text {os }}{ }^{-}$ free electrode at $0.1 \mathrm{~V}$ vs SHE, where electrochemical dark reduction reactions would be minimized (Figures $4 B, C$ and S16). A 2-4-fold enhancement in disk and ring currents suggests that the electron transfer pathway is occurring and can be enhanced by increased enzyme wiring via polymer embedding, which is consistent with analogous studies performed using a $\mathrm{C}_{60}$-containing derivative as the matrix. ${ }^{17}$ Enhanced cathodic photocurrents are also observed with the antennae, and the origin of this photocurrent likely stems from this electron transfer pathway.

We also tested for the possibility of reduction of $\mathrm{H}_{2} \mathrm{O}_{2}$ by $\mathrm{Chl} a$ and PSII in the absence of $\mathrm{O}_{2}$, which would likely occur only through electron transfer. Upon purging the solution with nitrogen and then titrating in $\mathrm{H}_{2} \mathrm{O}_{2}$, an increase in photocathodic currents was observed (Figure S17), likely originating from electron transfer to $\mathrm{H}_{2} \mathrm{O}_{2}$, forming water.

We next investigated the possibility of $\mathrm{H}_{2} \mathrm{O}_{2}$ generation through ${ }^{1} \mathrm{O}_{2}$ formation and its reduction on the electrode to give rise to the disk photocathodic currents. We first titrated in ${ }^{1} \mathrm{O}_{2}$ quenchers, 1,4-diazabicyclo[2.2.2] octane $(\mathrm{DABCO})^{36}$ or sodium azide, ${ }^{37}$ during our measurement and evaluated their effects on the disk currents. Quenching ${ }^{1} \mathrm{O}_{2}$ would eliminate its reduction at the electrode surface and the consequent cathodic currents from this process. Indeed, for both Chl $a$ and PSII, the photocathodic currents were slightly reduced upon the addition of either $10 \mathrm{mM}$ DABCO or $10 \mathrm{mM}$ sodium azide (Figure 4D and Figures S18, S19). In contrast, photocathodic currents (after an initial stabilization period of $5 \mathrm{~min}$ ) were much less affected by the exposure to the same light but in the absence of the ${ }^{1} \mathrm{O}_{2}$ quenchers. Control experiments performed by titrating in DABCO and sodium azide to a glassy carbon electrode with an adsorbed layer of an established ${ }^{1} \mathrm{O}_{2}$ generator, Rose Bengal (RB), also decreased the photocathodic currents (Figures 4D and S19C).

To verify the involvement of PSII-generated ${ }^{1} \mathrm{O}_{2}$, we performed experiments to selectively promote ${ }^{1} \mathrm{O}_{2}$ production by modulating the electron transport chain of PSII. We first titrated in inhibitors of the $\mathrm{Q}_{B}$ pocket, which would tune the energy redox level of $Q_{A}$ by anchoring into the $Q_{B}$ site. These would modify the redox levels of $Q_{A}$ and result in increased yield of ${ }^{1} \mathrm{O}_{2}$ by enhancing triplet formation. ${ }^{38,39}$ Addition of 1 mM DCMU or $1 \mathrm{mM}$ bromoxynil did not measurably modify the disk currents (Figure S20). This indicates that the effect conferred by the inhibitors did not result in a measurable increase of ${ }^{1} \mathrm{O}_{2}$ generation and reduction in our system.

We then turned to generating the doubly reduced $Q_{A}$, the quinol of $Q_{A}$, which results in an increase of the chlorophyll triplet yield and in increase of the chlorophyll triplet lifetime, both of which result in a marked increase of ${ }^{1} \mathrm{O}_{2}$ generation. ${ }^{40-42}$ We measured the cathodic photocurrents of a PSII electrode, where $\mathrm{Q}_{A}$ was doubly reduced by soaking in $100 \mathrm{mM}$ sodium dithionite and exposing it to $660 \mathrm{~nm}$ light. After subsequent removal and photoelectrochemical probing of the sample, the photocurrents were compared with those measured before the dithionite treatment of the sample (Figure $4 \mathrm{E})$. We observed a $\sim 5$-fold enhancement of photocathodic currents. This points to ${ }^{1} \mathrm{O}_{2}$ singlet formation and that ${ }^{1} \mathrm{O}_{2}$ reduction is also contributing to the disk currents. As controls, equivalent treatments of $\mathrm{Chl} a$ or LHCII electrodes, as well as soaking and illuminating a PSII electrode in a dithionite-free solution, did not lead to increased photocathodic currents (Figure S21).

We also demonstrated that the study of ROS formation is not entirely dependent on a conductive disk electrode, and the relative ROS formation rate with and without electrode reduction reactions can be quantified with our RRDE setup. Light-driven ring currents were compared in the rotating ring 
disk electrode setup from PSII adsorbed onto the ITO at a negative bias, held at open circuit ( $\sim 0 \mathrm{~V}$ vs SHE), and to PSII adsorbed on an insulating parafilm layer covering the disk electrode. We discovered that ROS can still be detected at the ring electrode in these situations, at approximately $25 \%$ and $4 \%$ relative to the ROS detected from the enzyme on a disk electrode at $-0.3 \mathrm{~V}$ vs SHE (Figure S22). Similar values were recorded for Chl a, CP43, LHCII, and the RC. These data indicate that $\mathrm{H}_{2} \mathrm{O}_{2}$ can be generated without the necessity of a negatively biased electrode in the proximity of the protein. The ring electrode currents observed without the negative bias may be due to the generation of chlorophyll-mediated ${ }^{1} \mathrm{O}_{2}$ production; the decrease in the current due to the insulating layer may reflect the role of the disk electrode reducing the ${ }^{1} \mathrm{O}_{2}$ to superoxide and/or peroxide. Protein oxidation would be a possible consequence of ${ }^{1} \mathrm{O}_{2}$ reduction without the reducing electrode environment. However, we cannot completely discount the electron transfer pathway from the Chl $a$ anion. These measurements provide an initial demonstration of the ability to study ROS in PSII that may be formed in vivo without the need for a negatively biased electrode.

\section{DISCUSSION}

We have established the rotating ring disk electrode technique as an effective method to study and quantitatively probe photosystem II. This work has resulted in several key findings.

(1) We have demonstrated the capability to quantitatively monitor $\mathrm{H}_{2} \mathrm{O}$ oxidation by PSII films on electrodes. Measuring $\mathrm{H}_{2} \mathrm{O}$ oxidation in real time will be further useful for assessing the compatibility of various electrode surfaces and for studying, for example, mechanisms of PSII assembly and photoactivation.

(2) Evidence for incomplete water oxidation with our PSII preparation in the RRDE system was not observed. We take this as an indication that the water-oxidizing enzyme functions normally when immobilized on the electrode. However, the rotating ring disk electrode system can be useful in future experiments for direct monitoring of incomplete $\mathrm{H}_{2} \mathrm{O}$ oxidation in PSII samples that have been specifically modified or chemically perturbed to selectively induce this reaction pathway. ${ }^{31-35}$

(3) Cathodic currents at the PSII-loaded disk electrode led to $\mathrm{H}_{2} \mathrm{O}_{2}$, detected at the ring electrode. $\mathrm{H}_{2} \mathrm{O}_{2}$ formed by $\mathrm{O}_{2}{ }^{\bullet-}$ is generated via two distinct pathways: (i) electron transfer to $\mathrm{O}_{2}$ by a chlorophyll anion, which is thought to be generated in an antenna chlorophyll exposed to the negatively biased electrode, and (ii) triplet energy transfer to ${ }^{3} \mathrm{O}_{2}$ from a chlorophyll triplet, which in PSII is generated by radical pair recombination within the reaction center core. The chlorophyll triplet route produces ${ }^{1} \mathrm{O}_{2}$, which is then reduced at the disk electrode. Evidence for the existence of each pathway was obtained by either (i) wiring the enzyme to the electrode with a redox-active polymer that may favor electron injection into the excited state chlorophyll or (ii) double reduction of $Q_{A}$, which is the well-established method for increasing the chloropyll triplet yield and lifetime in PSII. ${ }^{40-42}$ This points to the ability of the RRDE technique in this context to detect product formation and evaluate reaction pathways, and this allowed distinguishing between the electrode-induced chlorophyll anion pathway and the physiologically relevant chlorophyll triplet pathway. In relevance to PSII function in the thylakoid membrane, $\mathrm{H}_{2} \mathrm{O}_{2}$ formation from ${ }^{1} \mathrm{O}_{2}$ does not hinge on the presence of a negatively biased electrode, as ${ }^{1} \mathrm{O}_{2}$ may be easily reduced by a number of different species. Future work may permit lower yielding electron transfer pathways from cofactors on the electron transfer side ${ }^{4}$ to be distinguished from the two primary pathways studied here.

(4) Our RRDE apparatus demonstrated that the formation of $\mathrm{H}_{2} \mathrm{O}_{2}$ occurs without requiring a negatively biased electrode through experiments conducted with the proteins adsorbed on top of insulating layers. Such an experiment takes advantage of the well-defined reactant flux in an RRDE apparatus, which does not exist in a stationary electrochemical setup. This observation, coupled with the detection of ${ }^{1} \mathrm{O}_{2}$-generating pathways and study of $\mathrm{H}_{2} \mathrm{O}_{2}$ in a wide range ( 0.04 to 1.25 $\mathrm{mM}$ ) of oxygen concentrations, suggests that the rotating ring disk electrode system is potentially useful for studying the function of PSII in vivo. Furthermore, this line of experiments shows that $\mathrm{H}_{2} \mathrm{O}_{2}$ may be readily formed within the PSII natural environment via the reduction of ${ }^{1} \mathrm{O}_{2}$ through the oxidation of an amino acid residue, redox-active species, or the chlorophyll. In the future, thylakoids or even whole cells can be loaded on the disk electrode and subjected to a similar set of conditions.

Looking beyond PSII, photochemical reactions of photosystem I can be quantified. "Dark" enzyme electrocatalysts on photoelectrodes (i.e., hydrogenase on silicon photocathodes ${ }^{44}$ ) can also be probed. Pertinent mechanistic questions regarding photoactivation of biological units containing other oxidoreductases such as nitrogenases ${ }^{45}$ can now be addressed by detecting reaction intermediates and products with the RRDE. Extending beyond enzymes to whole cells, the study of redox mediator-based photocurrents of photosynthetic bacteria is another intriguing path to probe. In a larger context, the continuous development of methodology to investigate photosynthesis, such as that presented in this work, is crucial to understand this process.

\section{METHODS AND MATERIALS}

Biological Material. PSII, CP43, LCHII, and the RC were isolated according to previously established extraction and characterization procedures. ${ }^{46}$ PSII was extracted from Thermosynechococcus elongatus. A His-tagged CP47 mutant was the source of the PSII. ${ }^{46}$ The PSII cores were isolated through the use of $\mathrm{Ni}^{2+}$ affinity chromatography essentially as first described in ref 47. CP43, LHCII, and RC were all isolated from spinach. CP43 particles were isolated through ion-exchange chromatography from PSII particles that were tris-washed and solubilized with $\beta$-dodecyl maltoside. ${ }^{48}$ The RC complex was isolated through incubation with a nonionic detergent, purified through ion exchange chromatography, and lacked the plastoquinones, the nonheme iron, and the $\mathrm{MnCa}$ cluster. ${ }^{49}$ It contained four Chl $a$, two pheophytin, a cytochrome $b_{559}$, and two peripheral Chl a molecules. The materials described above were kept in the dark in liquid nitrogen before use. A freshly thawed aliquot was used for each set of measurements. Catalase (from bovine liver) and SOD (from bovine erythrocytes) were both purchased from SigmaAldrich. Prior to use, an appropriate amount ( $\sim 12 \mathrm{mg}$ in each case) was dissolved in $5 \mathrm{~mL}$ of the same buffer as used for the electrochemical experiments, and the solution was added directly to the electrolyte solution $(\sim 125 \mathrm{~mL})$. To generate Mn-depleted PSII,

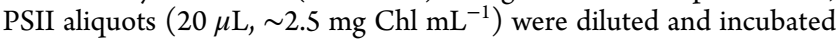
in buffer with reducing and chelating agents $\mathrm{NH}_{2} \mathrm{OH}(10 \mathrm{mM})$ and EDTA $(0.5 \mathrm{mM})$, respectively, on ice $\left(4^{\circ} \mathrm{C}\right)$, for $30 \mathrm{~min}$ in the dark. The solution was then washed and resuspended in MES buffer three times and finally resuspended in buffer to reach a $\mathrm{Chl} a$ concentration

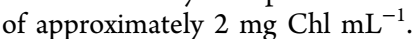

Electrode Preparation. All electrode preparation and material handling were conducted in a dark environment to minimize PSII photodamage. In all cases, a glassy carbon working electrode was used with a surface area of $0.2 \mathrm{~cm}^{2}$. Chlorophyll $a$ (Sigma-Aldrich, from 
spinach), $3 \mu \mathrm{L}$ of $100 \mu \mathrm{g} \mathrm{mL}^{-1}$ in ethanol, was drop cast onto a freshly polished glassy carbon surface and allowed to dry in the dark. ITO electrodes were prepared by drop casting $3 \mu \mathrm{L}$ of a stock of $20 \%$ by weight ITO ( $50 \mathrm{~nm}$, Sigma-Aldrich) in ethanol with $5 \mathrm{M}$ acetic acid onto a freshly polished glassy carbon surface and drying for $20 \mathrm{~min}$ at $80{ }^{\circ} \mathrm{C}$ in air. Following this, the electrodes were treated with UVozone for $15 \mathrm{~min}$. A $1 \mu \mathrm{L}$ amount of PSII, CP43, and LHCII were drop cast onto the ITO electrodes and dried for approximately 15 $\min$.

Electrochemical Measurements. An Alvatek Ivium CompactStat equipped with bipotentiostat capabilities was utilized for electrochemical measurements. Unless indicated otherwise, the electrolyte consisted of MES, $20 \mathrm{mM} \mathrm{CaCl}, 15 \mathrm{mM} \mathrm{MgCl}_{2}$, and $50 \mathrm{mM} \mathrm{KCl}$. The desired $\mathrm{pH}$ was reached through titration with an appropriate amount of $\mathrm{KOH}$ or $\mathrm{HCl}$. A double-junction $\mathrm{Ag} / \mathrm{AgCl}$ reference electrode and a glassy carbon rod counter electrode were used. The working electrode consisted of a glassy carbon disk $(0.2$ $\mathrm{cm}^{2}$ ) and, in cases of RRDE measurements, a Pt ring with dimensions of $6.5 \mathrm{~mm}$ inner diameter, $7.5 \mathrm{~mm}$ outer diameter enclosed in a PEEK body (Pine Research Instrumentation, E6R1 ChangeDisk). The mesoporous ITO was deposited from a solution consisting of $20 \mathrm{wt} \%$ ITO nanoparticles $(\sim 50 \mathrm{~nm}$ from Sigma-Aldrich) and $5 \mathrm{M}$ acetic acid. A $3 \mu \mathrm{L}$ amount of this solution was drop cast onto the glassy carbon disk and dried in an $80{ }^{\circ} \mathrm{C}$ oven for $30 \mathrm{~min}$ to remove the solvent and improve electrical connectivity between the particles. Following this procedure, the surface was subjected to a UV-ozone plasma treatment for 10 min to remove residual organic species. ${ }^{12}$

The electrode was rotated at $400 \mathrm{rpm}$ (Princeton Applied Research model 636A electrode rotator) to attain a steady reactant flux to the disk and ring surfaces. We employed a four-necked flask (one neck for working, counter, and reference electrodes and one neck as a gas inlet) at room temperature, with measurements being performed in a pH 6.5 electrolyte solution (unless specified otherwise). Our samples were illuminated from the bottom at $8 \mathrm{~mW} \mathrm{~cm}^{-2}$ by a $660 \mathrm{~nm}$ LED to closely match the Chl $a$ and PSII absorption. Current-voltage curves were recorded in a stepped chronoamperometry mode: the voltage on the disk electrode was systematically increased/decreased, and the working electrode was subjected to chopped illumination. The resulting light-induced currents were recorded, and their magnitudes (light-dark current) were used to plot data such as in Figure 2. For testing enhanced photocathodic currents through redox-polymer wiring, PSII and other units were mixed with a $10 \mathrm{mg} \mathrm{mL}^{-1}$ aqueous stock of a poly(1-vinylimidazole-co-allylamine)-Os(bipy) ${ }_{2} \mathrm{Cl}$ polymer (synthesized according to previously published procedures ${ }^{16}$ ), prior to drop casting on the ITO electrode. The total amounts of enzymes/ components were kept constant. Reductive activation $\left(\mathrm{Q}_{\mathrm{A}}\right.$ double reduction) of PSII was carried out by taking a PSII-loaded electrode that had been previously tested and soaking in a $\mathrm{pH}$ 6.5 MES buffer solution with $100 \mathrm{mM}$ sodium dithionite for $30 \mathrm{~min}$ and subjecting the PSII electrode to $5 \mathrm{~min}$ of illumination $\left(660 \mathrm{~nm}, 8 \mathrm{~mW} \mathrm{~cm}{ }^{-2}\right)$ in this solution, prior to rinsing with fresh electrolyte and testing again in the same experimental conditions. Error bars are generated from the standard deviation of typically 3-6 independent measurements.

To detect $\mathrm{H}_{2} \mathrm{O}_{2}$ and $\mathrm{O}_{2}{ }^{--}$through their electrochemical oxidation, the $\mathrm{Pt}$ ring electrode was held at $\sim 50 \mathrm{mV}$ negative of the thermodynamic $\mathrm{H}_{2} \mathrm{O}$ oxidation potential ( 1.18 vs the reversible hydrogen electrode, which was $\mathrm{pH}$ dependent in this case to provide the maximum electrochemical overpotential to ensure all available $\mathrm{H}_{2} \mathrm{O}_{2}$ and $\mathrm{O}_{2}{ }^{--}$were oxidized at the ring). This potential was also too negative to oxidize $\mathrm{H}_{2} \mathrm{O}$ or to oxidize $\mathrm{H}_{2} \mathrm{O}_{2}$ through a $1 e^{-}$oxidation. $\mathrm{O}_{2}$ was detected by reducing it at the ring electrode at $50 \mathrm{mV}$ positive of the thermodynamic hydrogen evolution reaction potential in an airfree environment bubbled with $\mathrm{N}_{2} . \mathrm{O}_{2}$ reduction measurements were performed with an air-saturated electrolyte $\left(0.26 \mathrm{mM} \mathrm{O}_{2}\right)$. In cases where DCMU was utilized, a stock of each was prepared in the dark (100 $\mathrm{mM}$ in DMSO) and an appropriate amount was added to achieve $1 \mathrm{mM}$ in the electrolyte solution. The collection efficiency of the RRDE (determined to be $26 \%$ by the manufacturer, Pine Research Instrumentation $)^{50}$ was quantified for both planar and mesoporous surfaces using a standard ferri/ferrocyanide redox couple across a range of rotation rates. This was recorded to be $26.0 \%$ and $25.2 \%$ at $400 \mathrm{rpm}$ for the planar and mesoporous geometries, respectively.

Chlorophyll a Quantification. After each measurement, the working electrode was sonicated in $1 \mathrm{~mL}$ of methanol to extract all Chl $a$ in the sample. Chl $a$ content was calculated using $\lambda_{665}(\varepsilon=$ $\left.79.95(\mathrm{mg} \mathrm{Chl} a)^{-1} \mathrm{~mL} \mathrm{~cm}^{-1}\right){ }^{51}$ In the case of materials adsorbed onto ITO films, the electrodes were first sonicated in methanol; then any remaining ITO was scratched off into the solution. The methanol solution was sonicated and the supernatant analyzed for Chl $a$ content.

\section{ASSOCIATED CONTENT}

\section{Supporting Information}

The Supporting Information is available free of charge on the ACS Publications website at DOI: $10.1021 /$ jacs.8b08784.

Additional experimental data and information (PDF)

Additional data related to this publication are available at the University of Cambridge data repository (https:// doi.org/10.17863/CAM.27714)

\section{AUTHOR INFORMATION}

\section{Corresponding Authors}

*a.rutherford@imperial.ac.uk

*reisner@ch.cam.ac.uk

ORCID ${ }^{\circ}$

Erwin Reisner: 0000-0002-7781-1616

\section{Author Contributions}

The manuscript was written through contributions of all authors. All authors have given approval to the final version of the manuscript.

Notes

The authors declare no competing financial interest.

\section{ACKNOWLEDGMENTS}

N.K. gratefully acknowledges the Royal Society Newton International Fellowship, NF160054. J.Z.Z. and E.R. acknowledge the European Research Council (ERC) Consolidator Grant "MatEnSAP" (682833). A.W.R. and A.F. were supported by Biotechnology and Biological Sciences Research Council (BBSRC) grants BB/K002627/1 and BB/R00921X/ 1. This work was also supported by the EPSRC (DTA Ph.D. studentship to K.P.S.) and French Corps of Bridges, Waters \& Forests (S.L). R.v.G. was supported by the VU University Amsterdam, the ERC Advanced Investigator grant (267333, PHOTPROT), the EU FP7 project PAPETS (GA 323901), and an Academy Professor grant from The Netherlands Royal Academy of Sciences (KNAW). We thank H. van Roon (VU University Amsterdam) for preparation of the spinach PSII samples and Dr. Adrian Ruff and Prof. Wolfgang Schuhmann (Ruhr-University Bochum) for providing Os-polymer samples. The authors also thank Dr. William Robinson, Esther Moore, and Dr. Nina Heidary (University of Cambridge) for helpful discussions.

\section{REFERENCES}

(1) Cox, N.; Pantazis, D. A.; Neese, F.; Lubitz, W. Acc. Chem. Res. 2013, 46, 1588-1596.

(2) Mirkovic, T.; Ostroumov, E. E.; Anna, J. M.; van Grondelle, R.; Govindjee; Scholes, G. D. Chem. Rev. 2017, 117, 249-293.

(3) Cardona, T.; Sedoud, A.; Cox, N.; Rutherford, A. W. Biochim. Biophys. Acta, Bioenerg. 2012, 1817, 26-43. 
(4) Pospísil, P. Biochim. Biophys. Acta, Bioenerg. 2009, 1787, 11511160.

(5) Krieger-Liszkay, A.; Fufezan, C.; Trebst, A. Photosynth. Res. 2008, 98, 551-564.

(6) Rutherford, A. W.; Osyczka, A.; Rappaport, F. FEBS Lett. 2012, 586, 603-616.

(7) Telfer, A. Plant Cell Physiol. 2014, 55, 1216-1223.

(8) Kale, R.; Hebert, A. E.; Frankel, L. K.; Sallans, L.; Bricker, T. M.; Pospísil, P. Proc. Natl. Acad. Sci. U. S. A. 2017, 114, 2988-2993.

(9) Prasad, A.; Kumar, A.; Suzuki, M.; Kikuchi, H.; Sugai, T.; Kobayashi, M.; Pospísili, P.; Tada, M.; Kasai, S. Front. Plant Sci. 2015, 6,862 .

(10) Cleland, R. E.; Grace, S. C. FEBS Lett. 1999, 457, 348-352.

(11) Brinkert, K.; Le Formal, F.; Xiaoe, L.; Durrant, J.; Rutherford, A. W.; Fantuzzi, A. Biochim. Biophys. Acta, Bioenerg. 2016, 9, 14971505.

(12) Kato, M.; Cardona, T.; Rutherford, A. W.; Reisner, E. J. Am. Chem. Soc. 2012, 134, 8332-8335.

(13) Kato, M.; Zhang, J. Z.; Paul, N.; Reisner, E. Chem. Soc. Rev. 2014, 43, 6485-6497.

(14) Sokol, K. P.; Mersch, D.; Hartmann, V.; Zhang, J. Z.; Nowaczyk, M. M.; Rögner, M.; Ruff, A.; Schuhmann, W.; Plumeré, N.; Reisner, E. Energy Environ. Sci. 2016, 9, 3698-3709.

(15) Kothe, T.; Plumeré, N.; Badura, A.; Nowaczyk, M. M.; Guschin, D. A.; Rögner, M.; Schuhmann, W. Angew. Chem., Int. Ed. 2013, 52, 14233-14236.

(16) Badura, A.; Guschin, D.; Esper, B.; Kothe, T.; Neugebauer, S.; Schuhmann, W.; Rögner, M. Electroanalysis 2008, 20, 1043-1047.

(17) Zhang, J. Z.; Sokol, K. P.; Paul, N.; Romero, E.; van Grondelle, R.; Reisner, E. Nat. Chem. Biol. 2016, 12, 1046-1052.

(18) Brinkert, K. Protein film voltammetry and spectroelectrochemistry of the electron acceptor site in Photosystem II. PhD Thesis, Imperial College London, August 2015.

(19) Mersch, D.; Lee, C.-Y.; Zhang, J. Z.; Brinkert, K.; FontecillaCamps, J. C.; Rutherford, A. W.; Reisner, E. J. Am. Chem. Soc. 2015, 137, 8541-8549.

(20) Parkin, A.; Seravalli, J.; Vincent, K. A.; Ragsdale, S. W.; Armstrong, F. A. J. Am. Chem. Soc. 2007, 129, 10328-10329.

(21) Blanford, C. F.; Heath, R. S.; Armstrong, F. A. Chem. Commun. 2007, 1710-1712.

(22) Kamin, R. A.; Wilson, G. S. Anal. Chem. 1980, 52, 1198-1205.

(23) Shu, F. R.; Wilson, G. S. Anal. Chem. 1976, 48, 1679-1686.

(24) Brocato, S.; Lau, C.; Atanassov, P. Electrochim. Acta 2012, 61, 44-49.

(25) Concepcion, J. J.; Binstead, R. A.; Alibabaei, L.; Meyer, T. J. Inorg. Chem. 2013, 52, 10744-10746.

(26) Boussac, A.; Rappaport, F.; Carrier, P.; Verbavatz, J.-M.; Gobin, R.; Kirilovsky, D.; Rutherford, A. W.; Sugiura, M. J. Biol. Chem. 2004, 279, 22809-22819.

(27) Edmund, C.; Tse, E. C. M.; Barile, C. J.; Kirchschlager, N. A.; Li, Y.; Gewargis, J. P.; Zimmerman, S. C.; Hosseini, A.; Gewirth, A. A. Nat. Mater. 2016, 15, 754-759.

(28) Malko, D.; Kucernak, A. Electrochem. Commun. 2017, 83, 6771.

(29) Bao, H.; Burnap, R. L. Front. Plant Sci. 2016, 7, 1-13.

(30) Rutherford, A. W.; Paterson, D. R.; Mullet, J. E. Biochim. Biophys. Acta, Bioenerg. 1981, 635, 205-214.

(31) Wydrzynski, T.; Ångström, J.; Vänngård, T. Biochim. Biophys. Acta, Bioenerg. 1989, 973, 23-28.

(32) Fine, P. L.; Frasch, W. D. Biochemistry 1992, 31, 12204-12210.

(33) Hillier, W.; Wydrzynski, T. Photosynth. Res. 1993, 38, 417-423.

(34) Frankel, L. K.; Sallans, L.; Limbach, P. A.; Bricker, T. M. Biochemistry 2012, 51, 6371-6377.

(35) Klimov, V.; Ananyev, G.; Zastryzhnaya, O.; Wydrzynski, T.; Renger, G. Photosynth. Res. 1993, 38, 409-416.

(36) Ouannes, C.; Wilson, T. J. Am. Chem. Soc. 1968, 90, 65276528.

(37) Harbour, J. R.; Issler, S. L. J. Am. Chem. Soc. 1982, 104, 903905.
(38) Müh, F.; Glöckner, C.; Hellmich, J.; Zouni, A. Biochim. Biophys. Acta, Bioenerg. 2012, 1817, 44-65.

(39) Krieger-Liszkay, A.; Rutherford, A. W. Biochemistry 1998, 37, 17339-17344.

(40) van Mieghem, F. J. E.; Nitschke, W.; Mathis, P.; Rutherford, A. W. Biochim. Biophys. Acta, Bioenerg. 1989, 977, 207-217.

(41) van Mieghem, F. J. E.; Searle, G. F. W.; Rutherford, A. W.; Schaafsma, T. J. Biochim. Biophys. Acta, Bioenerg. 1992, 1100, 198206.

(42) van Mieghem, F.; Brettel, K.; Hillman, B.; Kamlowski, A.; Rutherford, A. W.; Schlodder, E. Biochemistry 1995, 34, 4798-4813.

(43) Kozuleva, M. A.; Petrova, A. A.; Mamedov, M. D.; Semenov, A. Y.; Ivanov, B. N. FEBS Lett. 2014, 588, 4364-4368.

(44) Nam, D. H.; Zhang, J. Z.; Andrei, V.; Kornienko, N.; Heidary, N.; Wagner, A.; Nakanishi, K.; Sokol, K. P.; Slater, B.; Zebger, I.; Hofmann, S.; Fontecilla-Camps, J. C.; Park, C. B.; Reisner, E. Angew. Chem., Int. Ed. 2018, 57, 10595-10599.

(45) Seefeldt, L. C.; Dean, D. R.; Hoffman, B. M. Nitrogenase Mechanism: Electron and Proton Accumulation and $\mathrm{N}_{2}$ Reduction. In Molybdenum and Tungsten Enzymes; The Royal Society of Chemistry: Cambridge, 2016; pp 274-296.

(46) Sedoud, A.; Kastner, L.; Cox, N.; El-Alaoui, S.; Kirilovsky, D.; Rutherford, A. W. Biochim. Biophys. Acta, Bioenerg. 2011, 1807, 216226.

(47) Sugiura, M.; Inoue, Y. Plant Cell Physiol. 1999, 40, 1219-1231. (48) Groot, M.-L.; Frese, R. N.; de Weerd, F. L.; Bromek, K.; Pettersson, Å.; Peterman, E. J. G.; van Stokkum, I. H. M.; van Grondelle, R.; Dekker, J. P. Biophys. J. 1999, 77, 3328-3340.

(49) Romero, E.; Augulis, R.; Novoderezhkin, V. I.; Ferretti, M.; Thieme, J.; Zigmantas, D.; van Grondelle, R. Nat. Phys. 2014, 10, 676-682.

(50) Pine Research, E6R1 ChangeDisk Series. Retrieved from https://www.pineresearch.com/shop/wp-content/uploads/sites/2/ 2016/07/DRP10048-Electrode-Information-E6R1-Series-REV005. pdf, Accessed August 20, 2016.

(51) Porra, R. J.; Thompson, W. A.; Kriedemann, P. E. Biochim. Biophys. Acta, Bioenerg. 1989, 975, 384-394. 